\title{
Middle Hepatic Vein Roadmap for a Safe Laparoscopic Right Hepatectomy
}

\author{
Katharina Joechle, $\mathrm{MD}^{1}$, Eduardo A. Vega, $\mathrm{MD}^{1}$, Masayuki Okuno, MD, $\mathrm{PhD}^{1}$, Eve Simoneau, MD, $\mathrm{PhD}^{1}$, \\ Satoshi Ogiso, MD, $\mathrm{PhD}^{2}$, Timothy E. Newhook, $\mathrm{MD}^{1}$, David L. Ramirez, $\mathrm{MD}^{3}$, A. Alex Holmes, $\mathrm{MD}^{4}$, Jose M. Soliz, \\ $\mathrm{MD}^{4}$, Yun Shin Chun, MD ${ }^{1}$, Ching-Wei D. Tzeng, MD ${ }^{1}$, Jeffrey E. Lee, MD ${ }^{1}$, Jean-Nicolas Vauthey, MD ${ }^{1}$, and \\ Claudius Conrad, $\mathrm{MD}, \mathbf{P h D}^{1}$
}

\begin{abstract}
${ }^{1}$ Department of Surgical Oncology, Hepato-Pancreato-Biliary Surgery, The University of Texas MD Anderson Cancer Center, Houston, TX; ${ }^{2}$ Department of Surgery, Kyoto University, Kyoto, Japan; ${ }^{3}$ Department of Breast Medical Oncology, The University of Texas MD Anderson Cancer Center, Houston, TX; ${ }^{4}$ Department of Anesthesiology and Perioperative Medicine, The University of Texas MD Anderson Cancer Center, Houston, TX
\end{abstract}

\begin{abstract}
Background. When performing a right hepatectomy, the middle hepatic vein (MHV) should guide the parenchymal transection. MHV hotspots for bleeding can be anticipated when applying the previously developed MHV Roadmap to a minimally invasive approach. ${ }^{1}$ This video demonstrates application of the MHV Roadmap to perform a safe laparoscopic right hepatectomy.

Patient. A 44-year-old woman with a solitary and large breast cancer liver metastasis in the right liver was considered for a laparoscopic right hepatectomy following an excellent response to neoadjuvant chemotherapy. The MHV anatomy was reconstructed using automated vascular reconstruction software (Synapse, Fuji) ahead of surgery.

Technique. With the patient in the French position, the hilar vessels are exposed and the inflow is controlled. Parenchymal transection begins along the demarcation line. ${ }^{2,3}$ The constant relationship between the portal bifurcation and the V5 ventral and dorsal allows for easy intraparenchymal identification of the MHV. The parenchymal transection is performed in a convex fashion
\end{abstract}

Electronic supplementary material The online version of this article (https://doi.org/10.1245/s10434-018-7034-0) contains supplementary material, which is available to authorized users.

(C) Society of Surgical Oncology 2018

First Received: 14 February 2018;

Published Online: 21 November 2018

C. Conrad, MD, PhD

e-mail: claudius@cconrad.net to optimize exposure of the MHV. Using MHV guidance, the parenchymal transection is continued and V8 is safely identified. The operation is completed with division of the anterior fissure and right hepatic vein.

Conclusion. Outlining the MHV anatomy according to the MHV Roadmap preoperatively helps to anticipate hotspots of bleeding. Guidance along the MHV through the parenchymal transection allows for early identification of tributaries, thereby preventing injury and remnant liver ischemia.

ACKNOWLEDGMENT The University of Texas MD Anderson Cancer Center is supported in part by the NIH/NCI under Award Number P30CA016672.

DISCLOSURES The authors declare that they have no conflict of interest.

\section{REFERENCES}

1. Ogiso S, Okuno M, Shindoh J, et al. Conceptual framework of middle hepatic vein anatomy as a roadmap for safe right hepatectomy. HPB (Oxford). Epub 25 Sep 2018. https://doi.org/ 10.1016/j.hpb.2018.01.002.

2. Soubrane O, Schwarz L, Cauchy F, Perotto LO, Brustia R, Bernard $\mathrm{D}$, et al. A conceptual technique for laparoscopic right hepatectomy based on facts and oncologic principles: the caudal Approach. Ann Surg. 2015;261(6):1226-31.

3. Conrad C, Gayet B. Right hepatectomy. In: Conrad C, Gayet B, editors. Laparoscopic liver, pancreas, and biliary surgery. Chichester: Wiley; 2017. p. 410-5. 